\title{
Biofilm formation and antimicrobial resistance in methicillin-resistant Staphylococcus aureus isolated from burn patients, Iran
}

\author{
Solmaz Ohadian Moghadam, Mohammad Reza Pourmand, Farzaneh Aminharati \\ Department of Pathobiology, School of Public Health, Tehran University of Medical Sciences, Tehran, Iran
}

\begin{abstract}
Introduction: Burns are the most serious forms of trauma and a major cause of mortality worldwide. Methicillin-resistant Staphylococcus aureus (MRSA) is one of the most common pathogens of burn wound infections; treatment has faced serious problems due to antibiotic resistance in these strains. Biofilm formation, which increases antibiotic resistance capabilities and is considered to be a virulence factor, also causes treatment failure and recurrent staphylococcal infections in burn patients.

Methodology: A total of 135 pus/wound swabs were collected; $S$. aureus was identified by confirmatory tests. The $i c a A / D$ and $m e c A$ genes were detected in DNA extracts by polymerase chain reaction assay separately. To determine the prevalence of biofilm formation, a modified Congo red agar and the microtiter plate method were used. Investigation of antibiotic resistance was performed using the disk diffusion method.

Results: S. aureus (48.87\%) was identified in 65 (48.87\%) samples, of which 40 (61.53\%) were confirmed to be MRSA. Among MRSA and methicillin-sensitive S. aureus (MSSA) isolates, $97.5 \%$ and $60 \%$ produced biofilm, respectively. Resistance of MRSA isolates to amikacin, ceftriaxone, ciprofloxacin, erythromycin, gentamicin, mupirocin, rifampin, tetracycline, and tobramycin was $64.1 \%, 76.92 \%, 51.28 \%$, $87.18 \%, 71.8 \%, 10.26 \%, 5.13 \%, 89.74 \%$, and $61.54 \%$, respectively.

All MRSA and MSSA isolates were susceptible to fusidic acid, linezolid, teicoplanin, tigecycline, and vancomycin.

Conclusions: The high prevalence of biofilm-producing, drug-resistant $S$. aureus isolates in our study suggests that epidemiological studies on the characteristics of common strains found in burn centers and a definition of their antibiotic resistance pattern would be helpful for therapeutic decisions.
\end{abstract}

Key words: biofilm; antimicrobial resistance; MRSA; burn patients.

J Infect Dev Ctries 2014; 8(12):1511-1517. doi:10.3855/jidc.5514

(Received 03 July 2014 - Accepted 13 August 2014)

Copyright (C) 2014 Ohadian Moghadam et al. This is an open-access article distributed under the Creative Commons Attribution License, which permits unrestricted use, distribution, and reproduction in any medium, provided the original work is properly cited.

\section{Introduction}

Burns are the most common and serious form of trauma [1] and are still a major public health problem and a leading cause of mortality worldwide [2,3]. Due to the loss of protective barriers and consequently a reduction of cellular and humoral defense, microbial colonization and infection risk in patients hospitalized with burns is very high [3]. Staphylococcus aureus is one of the most common pathogens of burn wounds. It has the ability to generate a large number of virulence factors, which are important in pathogenesis and infectious invasion [4]. The global emergence of organisms with multiple drug resistances (MDRs), such as methicillin-resistant Staphylococcus aureus (MRSA), is an important factor in acute and chronic infections that leads to increased mortality rates and increased healthcare costs [5]. Difficulty in choosing appropriate antibiotics due to antibiotic resistance has limited the treatment of burn wound infections $[6,7]$.
In addition to antibiotic resistance, the other factor that causes treatment failure and chronic and recurrent staphylococcal infections in burn patients is biofilm formation in these strains [8,9]. Since the ability of biofilm production by MRSA increases antibiotic resistance, hospital patients infected with these strains are at serious risk for treatment failure [10]. Biofilm formation is considered to be a virulence factor because the microorganisms that establish in a burn wound biofilm fundamentally differ from suspended populations [11]. Biofilm acts as a barrier to antimicrobial agents and the host immune system that assists sustained bacterial colonization [12].

Biofilms are organized communities of bacterial cells that are accumulated in a polymeric matrix produced by bacteria and can be attached to living or inanimate surfaces [12,13]. Researchers have demonstrated that the first stage of staphylococcal infections is attachment to surfaces such as host 
tissues[14].Recently, studies about genes involved in biofilm formation and their role in staphylococcal infections have received a great deal of attention [15]. Molecular studies have shown that during the late stages of attachment, organisms are attached to each other to form biofilms. This is done through polysaccharide intercellular adhesin (PIA), which is synthesized by products of the icaABCDoperon [16].

Choosing an appropriate antibiotic for treatment of a bacterial infection mainly depends on knowledge about the characteristics of resident strains and their antibiotic susceptibility profiles. Thus, determination of the antibiotic susceptibility patterns in prevalent strains of burn units leads to appropriate treatment and a decrease in economic costs. Biofilm formation followed by development of higher antibiotic resistance is more crucial in burn patients than in other patients. The aim of this study was to determine the prevalence of biofilm formation among MRSA and methicillin-sensitive $S$. aureus (MSSA) isolated from burn wound infections and their antibiotic susceptibility patterns. MRSA and MSSA isolates were examined for production of slime by Congo red assay for the presence of the $i c a A / D$ genes required for the production of PIA or polymeric N-acetyl glucosamine, and for their ability to attach to substrate in the microtiter plate assay for biofilm development.

\section{Methodology}

\section{Bacteria isolates}

Between December 2012 and March 2013, a total of 135 pus/wound swabs from skin and soft tissue infections (SSTIs), were collected from patients in the Motahari burn care center affiliated with Tehran University of Medical Sciences (TUMS). The samples were immediately sent to the TUMS laboratory in transport medium and were then cultured on blood agar and incubated for 24 hours at $37^{\circ} \mathrm{C}$. Then $S$. aureus isolates were identified with the confirmatory tests (Gram's stain, catalase, coagulase and DNase tests, and mannitol fermentation on mannitol salt agar [MSA]).

\section{Confirmation of methicillin-resistant S. aureus (MRSA)}

Bacterial suspension of all $S$. aureus isolates equivalent to $0.5 \mathrm{McFarland}$ was prepared and cultured on Mueller-Hinton agar medium containing $2 \% \mathrm{NaCl}$ and oxacillin antibiotics $(6 \mu \mathrm{g} / \mathrm{mL})$, then incubated for 24 hours at $30^{\circ} \mathrm{C}$. The growth inhibition zones were interpreted using Clinical Laboratory
Standards Institute (CLSI) guidelines [17]; thus methicillin-resistant isolates were screened.

Bacterial DNA was extracted using a DNeasy kit (Qiagen, Valencia, USA) according to the manufacturer's instructions; lysostaphin enzyme was used in the first stage. The mecA gene was then detected in DNA extracts by PCR assay [18].

\section{Slime assay on modified Congo red agar (MCRA)}

All isolates were incubated for 72 hours under aerobic conditions at $37^{\circ} \mathrm{C}$ using the modified Congo red agar medium; this was performed three times for all isolates. The morphology of colonies was then interpreted based on colony color as red, almost black, black, and very black. Strains with red colonies were considered to be non-slime-producing, and strains almost black, black, and very black colonies were considered to be slime-producing [19].

\section{Microtiter plate assay}

The microtiter plate method was conducted as previously described [13]. Briefly, $200 \mu$ lof bacterial suspension grown in trypticase soy broth (TSB), supplemented with $1 \%$ glucose and diluted. A total of 1:100 was poured into the wells of sterile flatbottomed 96-well polystyrene tissue culture plates (200 $\mu 1$ of TSB supplemented with $1 \%$ glucose was used as the negative control) and incubated 24 hours at $37^{\circ} \mathrm{C}$. All tests were performed in triplicate. Washing was then performed three times for each well with sterile phosphate-buffered saline (PBS; $\mathrm{pH}$ 7.2). After that, the fixation step was done by air drying. Subsequently, the adherent biofilm layer was stained by crystal violet for 15 minutes at room temperature. This was followed by the washing steps. Then the plates were air dried and resolubilized with ethanol (95\%) for 30 minutes. Finally, the optical density (OD) of each well was measured at $570 \mathrm{~nm}$, and average OD value of negative controls and samples was calculated. Interpretation of results was described as follows:

ODs $\leq$ ODc $=$ no biofilm producer; ODc $\leq$ ODs $\leq$ $2 \times \mathrm{ODc}=$ weak biofilm producer; $2 \times \mathrm{ODc} \leq \mathrm{ODs} \leq 4$ $\times$ ODc $=$ moderate biofilm producer; $4 \times$ ODc $<$ ODs $=$ strong biofilm producer $(\mathrm{ODc}=\mathrm{OD}$ control negative, ODs $=$ OD samples). Staphylococcus epidermidis ATCC 35984 was used as the biofilm producer control strain.

\section{Identification of icaA/icaD genes}

PCR assays were used to detect the mecA, icaA, and icaD genes separately. The genes were amplified 
on an Eppendorf (Hamburg, Germany) thermocycler with a final volume of $20 \mu \mathrm{l}$ containing $10 \mu \mathrm{l}$ of Qiagen HotStarTaq master mix (Invitrogen, Carlsbad, USA, containing PCR buffer with $3 \mathrm{mM} \mathrm{MgCl} 2,400$ $\mu \mathrm{M}$ of each dNTP and 2.5 units HotStarTaq DNA polymerase), $1 \mu 1$ of each primer $(20 \mathrm{pMol}$, MecA, ICAA and ICAD) (Table1) [11,18], $6 \mu \mathrm{L}$ of RNasefree water, and $2 \mu \mathrm{l}$ of DNA template. The products were then electrophoresed on agarose gel and the presence or absence of any resulting bands was evaluated.

\section{Antibiotic susceptibility test}

The antibiotic susceptibility patterns were determined by the disk diffusion method (Kirby-Bauer test). This was carried out on Mueller-Hinton agar medium, and growth inhibition zones were measured and interpreted according to the CLSI guidelines [17]. The antibiotics used in this study included amikacin $(30 \mu \mathrm{g})$, ciprofloxacin $(5 \mu \mathrm{g})$, ceftriaxone $(30 \mu \mathrm{g})$, erythromycin $(30 \mu \mathrm{g})$, fusidic acid $(5 \mu \mathrm{g})$, gentamicin $(10 \mu \mathrm{g})$ linezolid $(30 \mu \mathrm{g})$, mupirocin $(5 \mu \mathrm{g})$, rifampin $(5 \mu \mathrm{g})$, tetracycline $(30 \mu \mathrm{g})$, teicoplanin $(30 \mu \mathrm{g})$, tigecycline $(15 \mu \mathrm{g})$, tobramycin $(10 \mu \mathrm{g})$, and vancomycin $(30 \mu \mathrm{g})$ (MAST Diagnostics, Merseyside, UK). S. aureus ATCC29213 was used as a standard strain.

\section{Results}

\section{MRSA distribution}

S. aureus was isolated from 65 (48.14\%) of 135 samples taken from SSTIs. Using phenotypic (disk diffusion method) and genotypic (PCR for detection of mecA gene) methods, 40 (61.54\%) isolates were confirmed to be MRSA.

\section{Slime production}

Slime production of MRSA and MSSA isolates were explored by culturing them on MCRA. Slimeproducing isolates developed almost black to very black colonies, and non-slime producers showed red colonies. All colonies were kept under observation for up to 72 hours. During this time, $97.5 \%$ and $60 \%$ of MRSA and MSSA strains, respectively, showed almost black to very black colonies. Colonial morphology of MRSA and MSSA isolates on MCRA after incubation for 72 hours is summarized in Table 2.

\section{Microtiter plate method}

Using the microtiter plate method due to the negative control OD $(\mathrm{ODn}=0.08)$, the majority of MRSA strains $(62.5 \%)$ were moderate biofilm producers $(0.16<$ ODs $\leq 0.32)$, and only one isolate (the same isolate that had produced red colony on MCRA medium previously) was considered to be a non-biofilm-producing strain $(\mathrm{OD} \leq 0.08)$. It should be mentioned that, according to the mean OD570 of the negative control (0.08), values between 0.08 and 0.160 $(2 \times 0.08)$ were considered to be weak biofilm producers, those between 0.160 and $0.320(4 \times 0.08)$ to be moderate biofilm producers, and values higher than 0.320 were considered biofilm producers (Table $3)$.

\section{Antibiotic susceptibility}

The antimicrobial susceptibility patterns of MRSA and MSSA isolates are presented in Table 4. The highest resistance rate was observed for both tetracycline and gentamicin among the MRSA isolates and for ceftriaxone among MSSA isolates. Resistance to rifampin and tobramycin was the lowest among MRSA and MSSA isolates, respectively.

Table 1. Target genes and their primers used in this study

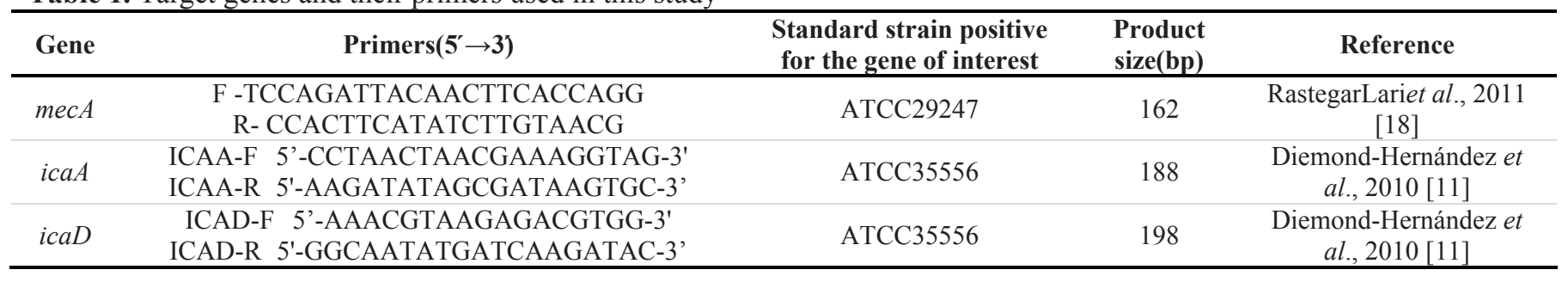

Table 2. Colonial morphology of MRSA and MSSA strains on CRA after 72 hours

\begin{tabular}{ccccccc}
\hline & \multicolumn{2}{c}{ MSSA } & & \multicolumn{2}{c}{ MRSA } \\
Red & Almost black & Black & Very black & Red & Almost black & Black \\
$\mathrm{N}(\%)$ & $\mathrm{N}(\%)$ & $\mathrm{N}(\%)$ & $\mathrm{N}(\%)$ & $\mathrm{N}(\%)$ & $\mathrm{N}(\%)$ & $\mathrm{N}(\%)$ \\
\hline $10(40)$ & $8(32)$ & $5(20)$ & $2(8)$ & $1(2.5)$ & $7(17.5)$ & $20(50)$ \\
\hline
\end{tabular}


Table 3. Results of biofilm production for MRSA and MSSA isolates using the microtiter plate method

\begin{tabular}{|c|c|c|c|c|c|c|c|}
\hline \multicolumn{4}{|c|}{ MRSA } & \multicolumn{4}{|c|}{ MSSA } \\
\hline $1(2.5)$ & $7(17.5)$ & $25(62.5)$ & $7(17.5)$ & $10(40)$ & $7(28)$ & $6(24)$ & $2(8)$ \\
\hline
\end{tabular}

${ }^{1}$. ODs ${ }^{*} \leq \mathrm{ODnc} 2$. ODnc $<\mathrm{ODs} \leq 2$.ODnc; 3. ODnc $<\mathrm{ODs} \leq 4$.ODnc; 4. ODnc $<$ ODs; ${ }^{*}$ :OD570nm of sample; ${ }^{* * *}$ : OD570nm of negative control

Table 4. Frequency of antibiotic resistance of MRSA and MSSA strains

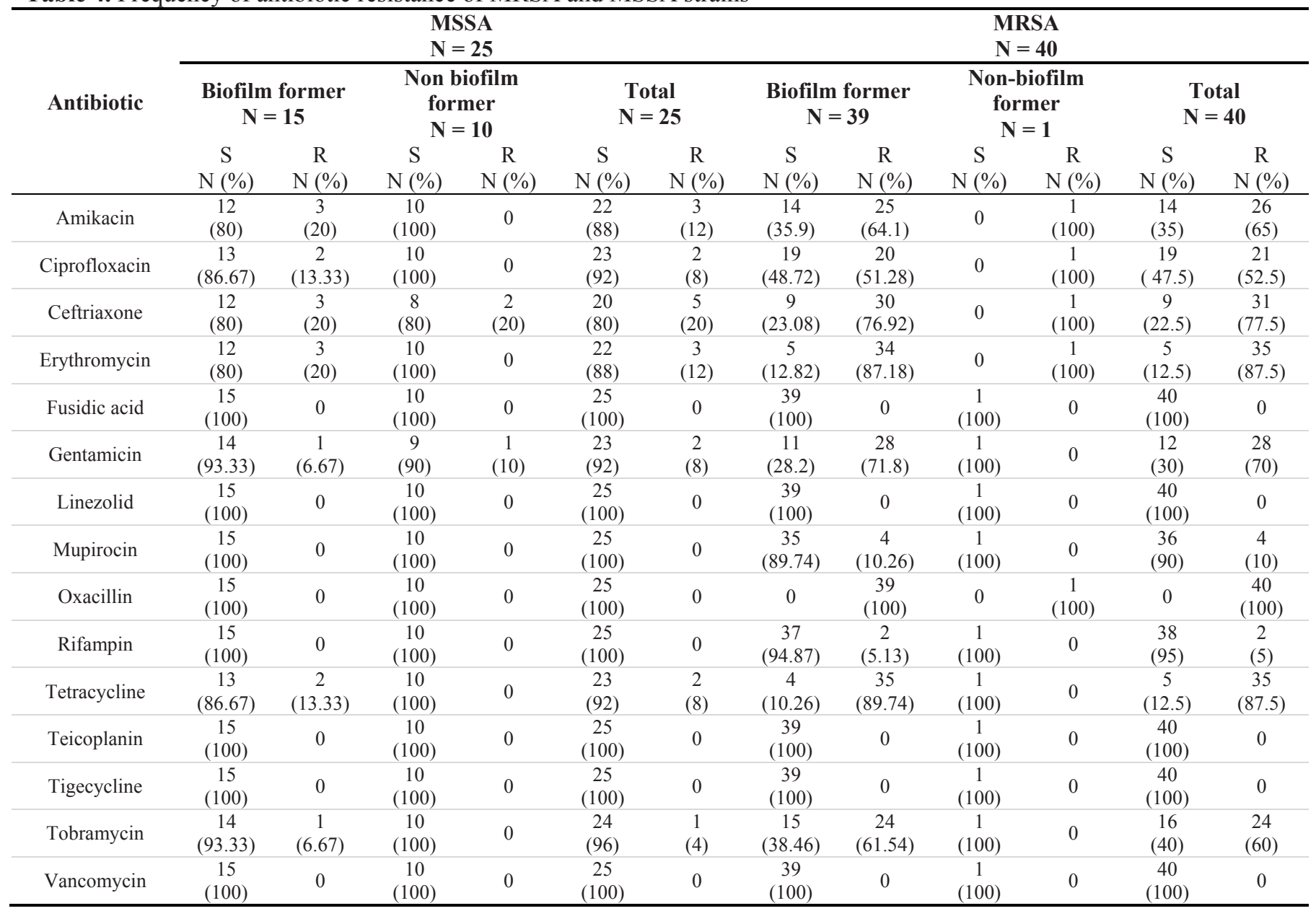


All MRSA and MSSA in this study were susceptible to fusidic acid, linezolid, teicoplanin, tigecycline, and vancomycin. Additionally, $66 \%$ of biofilm producer strains (MRSA and MSSA) were resistant to more than five antibiotics.

\section{Distribution of icaA/icaD genes}

All MRSA strains analyzed in this study were positive for the presence of icaA/icaD genes. The existence of the icaA/icaD genes in all biofilm producer MSSA isolates (15 isolates) was seen by PCR as well. These genes were absent among MSSA non-biofilm formers. The mecA gene was observed in all 40 MRSA isolates by PCR assay.

\section{Discussion}

Despite the development of control and prevention methods, bacterial infections are still the leading causes of death among burn patients [20]. Studies indicate that infections in burns lead to increased average lengths of stay in hospital that cost more than 800 dollar per case [21] and impose a very heavy cost to health systems worldwide [22]. Observance of infection control measures reduces infection, and this leads to reduction of diagnosis and treatment costs and to the emergence of drug resistance in clinical isolates [2]. Recently, several studies announced the increasing prevalence of MRSA [23]. Prevalence of MRSA varies in various burn units, which may be due to the implementation of different infection control policies. In the present study, $S$. aureus was among the most common pathogens isolated from SSTIs infections. This result is consistent with the results of other studies [24-26]. The prevalence rate of MRSA is different in various regions within a burn center. For example, this rate varies from a low of $33 \%$ in the United States [27] to a high of $98 \%$ in Korea [28]. This study showed that $S$. aureus was the causative agent of $48.14 \%$ of SSTIs, among which $61.54 \%$ were MRSA.

Challenges in the treatment of staphylococcal infections are accompanied by several mechanisms of biofilm formation in this bacterium [11]. There are several methods for the quantification of biofilm formation [29], but there is still no standard protocol for the detection of biofilm production. Although various methods are currently used for this purpose, the most widely used assay for evaluation of biofilm formation is the microtiter plate method [13].

In this study, morphology of colonies on MCRA was used to assess slime production. The microtiter plate method was used to evaluate and quantify the attachment ability of these strains. Microbial cell attachment to surfaces and the formation of multicellular communities is a key step in infection, and this characteristic is considered to be a virulence factor for the organism [30]. Using the microtiter plate method, all of the MRSA strains studied were found to produce biofilm except for one isolate; this rate was much lower $(60 \%)$ in MSSA isolates.

Slime production is characterized by diffusion of black pigment in MCRA, so strains with red or black colonies were interpreted as being non-biofilm producers and biofilm producers, respectively. Results of culturing on MCR to determine the prevalence of biofilm formation among MRSA and MSSA isolates were similar to the results of the microtiter plate method.

Our results demonstrated that all MRSA strains studied were positive for icaA/icaD genes. One of the MRSA isolates was positive for $i c a A / D$ genes but did not produce slime in the MCRA and microtiter plate methods. It would be interesting to follow up on this isolate, which may carry a mutation in one or more of the $i c a A / D$ genes or in the upstream region from which these genes are transcribed since $i c a A / D$ have been implicated as being necessary for biofilm formation in some studies. All MSSA isolates that formed biofilm were positive for the presence of $i c a A / D$ genes as well. Our results were consistent with some studies that emphasized the important role of $i c a A / D$ in biofilm formation [19]. Since the $i c a A / D$ gene is required for PIA, and PIA is required for attachment and biofilm production, it seems logical that all but one of the MRSA isolates produced biofilm. Perhaps there is a mutation in the $i c a A / D$ locus in the strain that has the genes but does not make PIA or biofilm. MRSA isolates that were resistant to multiple antibiotics were mostly biofilm producers, so it can be concluded that the majority of MDR pathogens are likely biofilm producers or vice versa. This result is in accordance with other studies [31,32]. Most hospital-acquired MRSA are also resistant to numerous other antibiotics. Furthermore, it is known that growth in biofilm makes any organism more tolerant to antibiotics to which they are susceptible as planktonic cells. Greatly enhanced tolerance to antibiotics is a characteristic of bacteria present in biofilms. MRSA strains are also resistant to numerous other antibiotics, especially when the strains are acquired in a hospital setting. This is a concern in the treatment of patients who are infected by such strains. All MRSA and MSSA in this study were susceptible to fusidic acid, linezolid, teicoplanin, tigecycline, and vancomycin. This finding 
is in agreement with other studies that have reported that MRSA is almost always susceptible to these antibiotics [33,34]. Therefore, these antibiotics can still be used for staphylococcal infections in burn patients in Iran. It seems that misuse and overuse of some antibiotics including tetracycline, gentamicin, and ceftriaxone have caused a high prevalence of resistance to them in this region; appropriate measures are needed to prevent treatment failures in burn patients. Thus, the presence of resistant strains and their antibiotic susceptibility patterns should be considered to plan serious procedures for their treatment and eradication. However, the tolerance of a strain in biofilm means that a different approach to therapy is needed, such as topical antibiotics, debridement to remove biofilm followed by more topical treatment, and systemic antibiotics to kill any planktonic cells dislodged. In conclusion, a high prevalence of biofilm-producing isolates involved in burn infections may indicate a potential outbreak of MRSA in the burn center, which is a problem that makes the treatment difficult and complicated. This emphasizes the necessity of antibiotic susceptibility monitoring of MRSA because knowledge about the epidemiology, characteristics of MDR strains, and spreading of such strains in a hospital setting, particularly in burn care facilities whose patients are immunodeficient, leads to the foundation of prevention and control programs that minimize the prevalence of subsequent infections due to such resistant strains.

\section{Acknowledgements}

This research was supported by Tehran University of Medical Sciences, Tehran, Iran (grant number:26590).

\section{References}

1. Church D, Elsayed S, Reid O, Winston B, Lindsay R (2006) Burn wound Infections. Clin Microbiol Rev 19: 403-434.

2. Naqvi ZA, Hashmi K, Kahral SA (2007) Methicillin-Resistant Staphylococcus aureus (MRSA) in burn patients. Pak J Pharmacol 24: 7-11.

3. Bloemsma GC, Dokter J, Boxma H, Oen IM (2008) Mortality and causes of death in a burn centre. Burns 34: 1103-1107.

4. Foster (2004) The Staphylococcus aureus superbug. J Clin Invest 114: 1693-6.

5. McGrath EJ, Asmar BI (2011) Nosocomial infections and multidrug-resistant bacterial organisms in the pediatric intensive care unit. Indian J Pediatr 78: 176-184.

6. Altoparlak U, Erol S, Akcay MN, Celebi F, Kadanali A (2004) The time-related changes of antimicrobial resistance patterns and predominant bacterial profiles of burn wounds and body flora of burned patients. Burns 30: 660-664.

7. Johnson A (2006) Antimicrobial agents: antibacterial and antifungals. J Antimicrob Chemother 58: 231. Doi:10.1093/jac/dk1218.

8. Stoodley P, Sauer K, Davies D, Costerton JW (2002) Biofilms as complex differentiated communities. Annu Rev Microbiol 56: 187-209.

9. Probert H, Gibson GR (2002) Bacterial biofilms in the human gastrointestinal tract. Curr Iss Intest Microbiol 3: 23-27.

10. Pozzi C, Waters EM, Rudkin JK, Schaeffer CR, Lohan AJ, Tong P, Loftus BJ, Pier GB, Fey PD, Massey RC, O'Gara JP (2012) Methicillin resistance alters the biofilm phenotype and attenuates virulence in Staphylococcus aureus device associated infections. PLoS Pathog 8: 8-12.

11. Diemond-Hernández B, Solórzano-Santos F, Leaños-Miranda B, Peregrino-Bejarano L, Miranda-Novales G (2010) Production of icaADBC-encoded polysaccharide intercellular adhesin and therapeutic failure in pediatric patients with staphylococcal device-related infections. BMC Infect Dis 10: 68-74.

12. Stepanović S, Vuković D, Hola V, Di Bonaventura G, Djukić S, Cirković I, Ruzicka F (2007) Quantification of biofilm in microtiter plates: overview of testing conditions and practical recommendations for assessment of biofilm production by staphylococci. APMIS 115: 891-899.

13. Atshan SS, Nor Shamsudin M, Sekawi Z, Lung LT, Hamat RA, Karunanidhi A, Mateg Ali A, Ghaznavi-Rad E, Ghasemzadeh-Moghaddam H, Chong Seng JS, Nathan JJ, Pei CP (2012) Prevalence of adhesin and regulation of biofilmrelated genes in different clones of Staphylococcus aureus. J Biomed Biotechnol 2012: 1-10.

14. Seo YS, Lee DY, Rayamahji N, Kang ML, Yoo HS (2008) Biofilm-forming associated genotypic and phenotypic characteristics of Staphylococcus spp. Isolated from animals and air. Res Vet Sci 85: 433-438.

15. Cucarella C, Tormo MA, Knecht E, Amorena B, Lasa I, Foster TJ, Penadés JR (2002) Expression of the biofilmassociated protein interferes with host protein receptors of Staphylococcus aureus and alters the infective process. Infect Immun 70: 3180-3186.

16. Chaieb K, Mahdouani K, Bakhrouf A (2005) Detection of $i c a \mathrm{~A}$ and ica $\mathrm{D}$ loci by polymerase chain reaction and biofilm formation by Staphylococcus epidermidis isolated from dialysate and needles in a dialysis unit. J Hosp Infect 61: 225230 .

17. Clinical and Laboratory Standards Institute (2011). Performance Standards for Antimicrobial Susceptibility 
Testing. Twenty-First International Supplement. M100-S21. CLSI: Wayne, PA.

18. Rastegar Lari A, Pourmand MR, Ohadian Moghadam S, Abdossamadi Z, Ebrahimzadeh Namvar A, Asghari B (2011) Prevalence of PVL-containing MRSA isolates among hospital staff nasal carriers. LabMedicine 42: 283-286.

19. Arciola CR, Baldassarri L, Montanaro L (2001) Presence of $i c a A$ and $i c a D$ genes and slime production in a collection of staphylococcal strains from catheter-associated infections. J Clin Microbiol 39: 2151-2156.

20. Ekrami A, Kalantar E (2007) Analysis of the bacterial infections in burn patients at Taleghani burn hospital in Ahvaz, Khuzestan province. Iran J Clin Infect Dis 2: 9-12.

21. Oncul O, Yüksel F, Altunay H, Açikel C, Celiköz B, Cavuşlu S (2002) The evaluation of nosocomial infection during 1year-period in the burn unit of a training hospital in Istanbul, Turkey. Burns 28: 738-744.

22. Safdar N, Bradley EA (2008) The risk of infection after nasal colonization with Staphylococcus aureus. Am J Med 121: 310-315.

23. Murray CK, Holmes RL, Ellis MW, Mende K, Wolf SE, McDougal LK, Guymon CH, Hospenthal DR (2009) Twentyfive year epidemiology of invasive methicillin-resistant Staphylococcus aureus (MRSA) isolates recovered at a burn center. Burns 35: 1112-1117.

24. Guggenheim $M$, Zbinden $R$, Handschin AE, Gohritz A, Altintas MA, Giovanoli P (2009) Changes in bacterial isolates from burn wounds and their antibiograms: a 20-year study (1986-2005). Burns 35: 553-560.

25. Ressner RA, Murray CK, Griffith ME, Rasnake MS, Hospenthal DR, Wolf SE (2008) Outcomes of bacteremia in burn patients involved in combat operations overseas. J Am Coll Surg 206: 439-444.

26. Fu Y, Xie B, Ben D, Lv K, Zhu S, Lu W, Tang H, Cheng D, Ma B, Wang G, Xiao S, Wang G, Xia Z (2012) Pathogenic alteration in severe burn wounds. Burns 38: 90-94.

27. Hodle AE, Richter KP, Thompson RM (2006) Infection control practices in US burn units. Mol Biol Rep 27: 142-151.
28. Song W, Lee KM, Kang HJ, Shin DH, Kim DK (2001) Microbiologic aspects of predominant bacteria isolated from the burn patients in Korea. Burns 27: 136-139.

29. Harraghy N, Seiler S, Jacobs K, Hannig M, Menger MD, Herrmann M (2006) Advances in in vitro and in vivo models for studying the staphylococcal factors involved in implant infections. Int J Artif Organs 29: 368-378.

30. Vaudaux P, Yasuda H, Velazco MI, Huggler E, Ratti I, Waldvogel FA, Lew DP, Proctor RA (1990) Role of host and bacterial factors in modulating staphylococcal adhesin to implanted polymer surfaces. J Biomater Appl 5: 134-153.

31. Sanchez CJ Jr, Mende K, Beckius ML, Akers KS, Romano DR, Wenke JC, Murray CK (2013) Biofilm formation by clinical isolates and the implications in chronic infections. BMC Infect Dis 13: 47-53.

32. Pourmand MR, Abdossamadi Z, Salari MH, Hosseini M (2011) Slime layer formation and the prevalence of $m e c A$ and aap genes in Staphylococcus epidermidis isolates. J Infect Dev Ctries 5: 34-40. doi:10.3855/jidc.984.

33. Naimi TS, LeDell KH, Como-Sabetti K, Borchardt SM, Boxrud DJ, Etienne J, Johnson SK, Vandenesch F, Fridkin S, O'Boyle C, Danila RN, Lynfield R (2003) Comparison of community- and health care-associated methicillin-resistant Staphylococcus aureus infection. JAMA 290: 2976-2984.

34. Popovich KJ, Hota B (2008) Treatment and prevention of community-associated methicillin-resistant Staphylococcus aureus skin and soft tissue infections. Dermatol Ther 21: 167179.

\section{Corresponding author}

Mohammad Reza Pourmand

Department of Pathobiology, School of Public Health

Tehran University of Medical Sciences, 100 Poursina St.,

Keshavarz Blvd., Tehran, Iran

Phone/Fax: +98 2188954910

Email: mpourmand@tums.ac.ir

Conflict of interests: No conflict of interests is declared. 